\title{
Struggling for Recognition? Strategic Disrespect in China's Pursuit of Soft Power
}

\author{
Jukka Aukia ${ }^{1}$
}

Received: 19 April 2019 / Accepted: 3 November 2019 / Published online: 20 November 2019

(C) The Author(s) 2019

\begin{abstract}
This paper addresses the Chinese policy community's interpretations of identities, which potentially shape the soft power policies of China. It couples soft power to identity through a discourse analysis of the language used by the Chinese state in relation to soft power. It builds on a number of earlier theorizations that associate soft power with identity as a discursive phenomenon. The results highlight the use of strategic disrespect in China's soft power discourse. In the context of global cultural competition, and in particular the South-South cooperation framework, it is argued that the practitioners of the Chinese discourse present China's 'Self' as a soft power and the Western 'Other' as a hard power.
\end{abstract}

Keywords Recognition seeking $\cdot$ Soft power $\cdot$ Identity $\cdot$ Political discourse

\section{Introduction}

Soft power is often connected to attractive cultural, ideological, and political resources. Understood as 'the ability to get what you want through attraction rather than coercion or payments' [36], soft power as a concept and practice has become popular among states and political practitioners. Using the tools of public diplomacy and nation branding, soft power is usually built by raising awareness of a state's attractive resources among international audiences. The success of state soft power therefore depends on how attractive audiences find the respective resources.

While soft power has gained popularity in policy circles, for many states, identity concerns have today become as important as security and welfare goals [17]. States create identities and have them recognized by other states and international audiences [40]. A successful identity - understood as the narrative you tell others about yourself as a self-description - requires the story to be recognized by your peers [16]. It is therefore

Jukka Aukia

jukka.aukia@utu.fi

1 Centre for East Asian Studies, University of Turku, Turku, Finland 
a reasonable argument that an identity that is found attractive is more likely to be recognized. On a general level, this connects identity narratives to soft power, but what exactly makes an identity attractive and how does soft power work in identity-related issues?

In seeking to clarify these questions, this study aligns itself with prior research that views soft power and identity construction as a discursive and linguistic phenomenon. These studies seek distance from the abovementioned resource/impact-based understanding of soft power, in favour of an identityrelated narrative construction $[4,45,14,38]$.

The example of the People's Republic of China (PRC) illustrates empirical connections between state identity narratives and soft power, best presented in the context of the official humiliation narrative of the PRC. According to this self-description, China suffered 100 years of humiliation first under colonial and then imperial rule [6]. This narrative implies not only that China has hitherto been insufficiently recognized by others but also that the disrespect directed towards China by Western liberal democracies is ongoing. To counter the perceived violation to her national character and mode of government, China's ruling Communist Party (CCP) applies the tools of public diplomacy. The aim is to tell the world the 'true' story of the PRC as a benevolent and responsible actor. Recognition of this identity would imply that audiences find it attractive, thus creating soft power for the Chinese state.

This article therefore addresses the connections between soft power and identity recognition in the context of China. It specifically examines the ways in which the CCP policy community uses soft power identities as a discursive practice. I argue that the practitioners of the soft power-related discourse strategically deploy disrespect, expecting their audiences to be emotionally invested in the identity-related perception. To further enhance the 'Self', the practitioners also 'Other' the West. In fact, I suggest that the PRC soft power discourse depicts the Self (China) as a soft power and the Other (the West) as a hard power, which is in line with the recent findings of Hagström and Pan [19]. Many practitioners of the soft power-related discourse also seek to destabilize the Western Self. In particular, the discursive practice appears to exploit existing Western power relations and the assumed internal perceptions of disrespect in the West. This is accomplished by addressing elites vs. commoners and North vs. South controversies.

While the focus of this paper is not on audience reception per se, I draw empirical data from two separate sources: Chinese language academic publications and English language Chinese state media articles. The purpose is to highlight the ways in which soft power identities are produced and formed by the Chinese academic policy community and to establish the presence of similar identity narratives in China's English language state media. Assuming that identities are constructed through discourse and that soft power can be built by deploying identity narratives of Self/Other, the relational approach thus formulated necessitates a prior relation between authors and audience. Therefore, to highlight the linguistic relation between those speaking on behalf of China and the intended audience, I underline discursive similarities between the Chinese policy community and the Chinese state media in targeting English-speaking audiences.

In the following sections, I first discuss soft power and identity formation as a discursive phenomenon. I propose that disrespect could function as an affective 
investment in identity-related discourses. Before providing an empirical discourse analysis, I present method-related issues. Finally, in the discussion section, I place the results within in the context of global cultural competition, in particular, within the South-South cooperation framework that China applies to its various bilateral and multilateral relations.

\section{Theory: How does Soft Power Work as a Discourse?}

In conceptualizing soft power as a language instead of a resource-based phenomenon, I start by clarifying the ways in which prior research has discussed identities as a discursive construction. Interestingly enough, recent work in the field of relational constructivism has focused on East Asia [48, 18, 31]. The understanding of relational constructivists is that identity in international politics is produced through linguistics. Language is seen as ontologically significant, where particular attention is paid to the categories of Self and Other. The consequent assumption is that knowledge of state behaviour can be studied by analysing the language used to construct state identities ([20], p. 18). The relational approach is well suited to the study of not only the dynamics of identity-making and differentiation but also related issues such as status (e.g. Duque [10]). Rebekka Adler-Nielssen and Alexei Tsinovoi [2], for example, explain identities as linguistic practices of international affairs. Essentially, within relational constructivism, there is consensus that dynamics of national identitybuilding occur in a discursive space, where state and non-state actors articulate themselves and others.

Furthermore, in seeking to connect soft power to identity, there is the central question of what makes an identity attractive to some and not to others. In answering, I join a body of soft power-related work that theorizes on attraction as a sociolinguistic phenomenon. The approach challenges resource-impact conceptions of soft power (for instance, Joseph Nyes [36]) and couples soft power to identity narratives. In an influential essay, Janice Bially Mattern [4], for example, questions the resource-based understanding of soft power. Through what she refers to as representational force, Mattern views soft power as a language-based force that builds attraction through identity-related narratives. Drawing on Jurgen Habermas's conceptualization of persuasion, Mattern ([4], p 606) ultimately argues that attractiveness is an interpretation selected from other interpretations through communication. Regarding China, Pan Chengxin and colleagues adopt a similar discursive take. In their view, soft power is produced through media discourses of identity. As one of various strategies to create attractive identities, Pan and colleagues refer to the well-known 'charm offensive' and to what they term the 'othering offensive' ([38], p. 5-6). While the former refers to a discursive strategy to construct Self in a positive light, the latter refers to a strategy to construct a negative and repulsive Other as a foil to the attractive Self.

Valentina Feklyunina effectively summarizes the above when she states that soft power manifests as a relationship rather than as a resource:

"[...] soft power is significantly more likely to be present in a relationship between actors who broadly see themselves as part of the same socially constructed reality, which would entail compatible interpretations of their identities, compatible understandings of their interests and compatible definitions of the situation." ([14], p. 777). 
The gist of this argument is that in finding common ground on identity-related issues, in the broader policy-making context the influence of soft power may manifest in making some decisions more likely than others.

\section{Disrespect as an Affective Investment}

Recognizing the importance of these theorizations, Ty Soloman [45] criticizes the approach for leaving out emotional aspects. To supplement and to capture the nature of attraction more effectively, Solomon introduces the concept of affective investment. In his view, attraction is successful not because of verbally expressed words, but because audiences are emotionally invested in identity narratives ([45], p. 726). While agreeing that identities are discourse dependent, Solomon points out that emotions play a crucial role in intersubjective relations, identities, and thus soft power. Therefore, while identities are constructed through discourse, for the sake of stability, there must be an affective investment in order to create soft power ([45], p. 728-729).

Following Solomon's argument, my proposal is that in the case of PRC soft power and identity discourses, disrespect could function as an affective investment. To place disrespect as an affective investment, and to explain how it functions as a social process, I use the classical Hegelian model, which international relations (IR) scholars use extensively to study international politics of recognition (e.g. Ringmar [40]). In terms of this model, every individual has a basic need to receive recognition from other human beings. However, unlike other basic needs (shelter, food) that can be obtained without changing the composition of the individual, the process of attaining recognition influences what kind of a person the individual becomes. Therefore, the creation of the Self requires the recognition of the Other ([16], p. 348).

Hegel's notion of the human need for recognition can also be applied to interstate relations and proceeds in a certain pattern of social interaction ([16], p. 349). In such interaction, identities are constructed through two consequent perspectives. Actors first tend to sell themselves accounts, stories, or narratives of themselves through which identities are built. These accounts are then tested in interaction and communication with others, who might or might not agree ([40], p. 6-7). Consequently, if an actor's narrative is declined and the need for recognition is denied, a perception of disrespect results ([22], p. 202).

Importantly, within recognition studies, the perception of disrespect is considered both strategic and nonstrategic. Strategic calculations may be beneficial under multiple circumstances and should be distinguished from emotional perceptions of nonrecognition. Interestingly, strategic planning of recognition politics is situated within a field that is considered as relevant for state actors in the domestic arena as it is for those in the international arena [32]. As China scholars are quick to point out, the Chinese state envisions soft power for both foreign use to brand the nation and domestic use to create political legitimacy. Barr [3], for example, demonstrates how China's soft power deployment is as critical domestically as it is externally.

In the following sections, I connect these insights empirically by addressing ways in which nonrecognition is employed in PRC identity discourses to create attraction. Strategic disrespect as an affective investment appears to be the common ground the PRC seeks to establish both abroad and at home. 


\section{Methods and Data}

Within IR, relational constructivists more often than not employ discourse analysis to study how language enacts specific identities. However, identities function in the realm of perceptions, thus making them incomplete. That is to say, identities are in a constant state of instability, where agreements over Self, and the view of the Self by Others, are difficult to achieve [2].

This poses challenges for analysis; it is possible that identity boundaries are blurred and thus difficult to observe. The application of a discourse analysis thus requires acceptance of the fact that the discursive construction of the Self rests on the basis of highlighting differences between the Self and Others. An analysis of these differences can, for example, be accomplished through identifying particular signs that form the discourse ([23], p. 26). These signs are linked to each other in building relations of sameness and are central in constituting representations of Self and Other. As Lindgren and Lindgren ([31], p 381) propose, a key task of a discourse analysis in relation to regarding identity construction is to observe the ways in which signs are relationally linked to each other.

Moreover, to make clear distinctions between identity boundaries, I also examine the Chinese discourse to identify strategies to construct persuasive arguments. In particular, self-categorization arguments are usually produced explicitly or implicitly within political discourses and can be based on significant or insignificant differences between categories. These arguments typically stereotype subject positions of Self and Other [49]. They also sharpen the boundaries between the in-group and the out-group ([25], p. 822 ) by focusing on the negative aspects of an out-group, such as defects and deficiencies [5].

Therefore, by applying discourse analysis, I specifically identify arguments of selfcategorization within the language and the ways in which they are relationally linked to each other. I also identify emotional aspects such as idealized self-images, expressions reinforcing the notion of 'us' and 'them', feelings of humiliation, as well as strategic elements. The identification of the latter includes observing the frequency of strategic expressions that refer, for example, to reputation or credibility ([32], p. 220-221).

A total of 30 journal articles, newspaper articles, and policy papers were used for the analysis. In order to select a representative sample, I used the key words 'soft power', 'public diplomacy', and 'Joseph Nye' in searching the $\mathrm{CNKI}^{1}$ database containing Chinese language academic research papers. Each text was selected independently of the others; in other words, a random selection of relevant journal articles was carried out. The Chinese language articles selected were published in mainland China between 1993 and 2017. While the sample is relatively small, I regard the data selection as representative of the Chinese discourse: the selected sample can be considered as diverse as the population.

A simple random sampling, such as the one conducted here, can in some cases be considered an unbiased representation of the total group. In selecting Chinese academic journal articles, this results from the lack of academic autonomy that makes the study of domestic politics in China an underdeveloped field. For example, He [21] and Wu [54] criticize Chinese academics for a pro-government approach in which official

\footnotetext{
$\overline{{ }^{1} \text { http://new.oversea.cnki.net/index/ }}$
} 
endorsement is preferred over peer review in judging the quality of research. Zhu and Pearson [59] also argue that the state is rarely critically considered in Chinese academic literature. Therefore, while often lacking academic rigour, the domestic political research conducted in Chinese and published in mainland China (1) is rather homogeneous in nature and (2) has the potential to provide insight into the general attitudes of the party-state and official party line.

Although the soft power rhetoric has various sources involving a fairly large number of practitioners within the PRC policy community, for the above reasons, I consider the opinions of scholars useful because they potentially reflect the official views, concepts, and accepted approaches. I agree, nonetheless, with Wuthnow [56] in disclaiming that the influence of individual discourse participants within the Chinese policy community does not vary and that the positions presented by them do not necessarily influence actual foreign policy behaviour.

In applying a linguistic approach to identity and soft power - as the current study does - the existence of a prior relation between these two concepts should be assumed, to which the speakers and their audience similarly subscribe. As the discourse of China's domestic policy community remains alien to the anglophone audience, I highlight also the linguistic relation between those speaking on behalf of China and the intended audience. This is accomplished by analysing English language texts of Chinese state media aimed at international audiences. Therefore, the empirical analysis is divided into three subsections: the Other, the Self, and the supporting discourse that targets an international audience.

\section{Analysis}

\section{Domestic Discourse relative to Other}

The underlining assumptions and guiding principles of the soft power-related discourse have been under development in China since the turn of the century and can be observed in the related language. It is typical of the kind of argumentation encountered that Chinese scholars seek to differentiate their approach from the original US soft power concept coined by Joseph Nye. Zhao, Li, and Cai [58], ${ }^{2}$ for example, underline the need to differentiate the Chinese views from the soft power theory originating from the "American discourse" and to enhance the soft power of China by developing a theory on the basis of local traditions. They refer to Liu [34] as follows: ${ }^{3}$

Presently the theoretical point of China's soft power construction is neither the traditional view of comprehensive national power, nor the western-style soft power theory but the soft power theory with Chinese characteristics (Quoted in Zhao, Li and Cai [58], p. 41. See also Liu [34]).

In the pro-government discourse at the time, therefore, two broad but interconnected dimensions could be observed: first, a need to move towards Chinese formulations

\footnotetext{
${ }^{2}$ Zhao Xiufang, Lecturer at School of Political and Public Administration, University of Jinan

${ }^{3}$ Liu Xienshang, Research Scientist at the Institute for Science, Technology, and Public Policy, Texas USA
} 
based on the original idea, and second, indications of ambitions to juxtapose the soft power of the US and China. Liu [33], for example, claims that soft power provides a new angle in researching the nature of American hegemony. According to his argument, the rapid expansion of US soft power after the Cold War promoted 'Americanization' within the processes of globalization, changing the dynamics of power competition and raising historical challenges not only for developing countries but also for major Western nations. In a more recent study, Wang [51] $]^{5}$ employs a practical argument in calling for more protective and proliferating measures regarding the national Chinese film and television industries, as they were 'under attack by foreign cultures' (Zhongguo chuantong wenhua zai wailai wenhua chongji xia). Using the notion of 'cultural imperialism' (wenhua diguozhuyi) he expresses fears that through Hollywood, the Chinese may start to turn towards American values (Meiguo de jiazhi guannian). Wang notes that the Chinese television and film industry has a long way to go to protect national Chinese culture. Similarly, Li [29] ${ }^{6}$ recognizes US popular culture as dominant, which has enabled it to 'control the global cultural discourse' (kongzhizhe quanqiu de wenhua huayu).

The exhibited identity classification between 'them' as abnormal, dominant, and intrusive and 'us' as normal and vulnerable has been a recurring argumentative tool in the Chinese soft power discourse. This is evident through references to cultural imperialism and attacking foreign cultures. Another frequently used way of constructing the same position has been by making reference to not only the US but to the West in general. $\mathrm{Wu}[53],{ }^{7}$ for example, identifies 'cultural homogenization' (wenhua shang de tongzhihua) followed by globalization causing 'blurring of national cultural identity' (minzu de wenhua shenfen ye bian de mohu). This would lead to 'anxiety and crises' (jiaolu yu weiji) for non-Western cultures, especially China. He regarded globalization as proliferating 'foreign cultural hegemony' (wailai wenhua baquan), 'cultural colonialism' (wenhua zhimin), and 'general public westernization' (shehui dazhong xifang hua).

Besides seeking distance from China's main rival, the USA, users of such rhetoric have laid down demarcations between the West and non-West, that is, China. Globalization, proliferation of the market economy and modernization have subsequently been classified as belonging to the former and not to the latter. Moreover, these subject positions have been further constructed by implying that in the West 'modern' is considered as good, while 'traditional' - in reference to the non-West - is regarded as bad. Considering these types of categorizations represented in the rhetoric, it is rather easy to notice that they are placed in the context of global cultural competition, where China is regarded as the underdog. Li [29], for example, made a normative argument to the effect that modern globalization consists of Western institutions and ideas. Western institutions and ideas take shape in 'global expansion' (quanqiu de kuozhang) and have thus grown to 'represent the advanced culture' (daibiao xianjin wenhua), which leads to a lack of Chinese cultural confidence. It is ironic that the subject position of a lack of cultural confidence in China has been connected to globalization, of which China - in

\footnotetext{
${ }^{4}$ Liu Debin, Director at the Centre of Contemporary International Relations Studies, Jilin University

${ }^{5}$ Wang, SuYa, Zhengzhou University School of Journalism and Communication

${ }^{6}$ Editorial Department of Journal of Shangluo University

${ }^{7} \mathrm{Wu}$ Xueli, Provincial Party School. Shandong
} 
economic terms - is among the most prominent beneficiaries. Moving this position further, $\mathrm{Su}$ [46] argues that China is threatened by 'Western cultural hegemony' (xifang wenhua baquan), 'export of Western democracies' (xifang minzhu shuchu), and 'religious penetration' (zongjiao shentou). Moreover, Wang [52 $]^{8}$ demonstrated how Western impact is the reason why Chinese academia is interested in cultural confidence, hinting at why this is studied from both 'historical and realist perspectives' (lishi he xianshi de weidu). The realist perspective seems to position China in cultural competition with the West as a realpolitik fact. A distinctive feature of soft power rhetoric has therefore been the mapping of contemporary menaces to Chinese cultural, political, and social existence. As demonstrated above, Chinese scholars have identified such menaces in the categorization schemes of globalization and decadent Western culture.

A number of interesting solutions to these perceived world order problems have been suggested. For example, Liu [35] ${ }^{9}$ connects ideology to Chinese cultural soft power, arguing that the enhancing of national soft power is a 'cultural path to ideological security' (yishi xingtai anquan de wenhua lujing). For this reason, Liu suggests establishing a national cultural security strategy to build a 'great cultural security wall' (wenhua anquan changcheng) against 'Western cultural invasion' (xifang wenhua de qinxi). Zhao, Li, and Cai [58] continue the criticism of US soft power and American cultural hegemony by proposing measures to respond in defence of 'Chinese cultural security' (wenhua anquan). Indeed, to encounter Western values and institutions, the Chinese argument has been to strategically strengthen the soft power of China.

\section{Domestic Discourse relative to Self}

The above undertaking to reduce the image of the West in general and the USA in particular was made in the context of Chinese image of the Self. This is evident through arguments that reflect on the developments within Chinese society. In these arguments, it is not only the perceived threat of globalization but also the recent ideological turnaround in economic thinking that is perceived to create social anomie or, as $\mathrm{Wu}$ $[53]^{10}$ puts it, a 'national sense of apathy' (minzu yishi danmo). Referring to hierarchical positioning, Lee [27] questions the mental state of the Chinese population. He argues that transitions in Chinese society are resulting in the mentality of some people ${ }^{11}$ 'getting gradually out of balance' (jian shiheng), 'the moral sense getting confused' (daode yishi chuxian-mimang), and their 'values being distorted' (jiazhi quxiang fasheng niuqu).

Relating to perceived 'national apathy', a tendency to apply further in-group definitions and self-categorization stereotypes can be observed. Xiao [57], ${ }^{12}$ for example, depicts the post-Marxist or the reform era as 'drastic change' (sudong jubian) and adds that 'people's thoughts were shocked' (ren de sixiang chansheng dongyao) and 'feelings for the future confused' (dui weilai de fazhan gandao mimang). Xiao seems

\footnotetext{
${ }^{8}$ Teresa Wang, School of Marxism, Wuhan University

${ }^{9}$ Liu Cuiyu, School of Humanities and Law, Henan Agricultural University

${ }^{10}$ Shandong Provincial Party School

${ }^{11}$ To refer to 'some people' is a typical rhetorical choice for the PRC policy elites when discussing political opposition

${ }^{12}$ Xiao Weiwei, College of Marxism, Central China Normal University
} 
convinced that an understanding of Marxism had practical significance and that the 'strengthening of faith in communism is of crucial importance' (jianding gongchan zhuyi de xinnian youzhe zhi guan zhongyao de yiyi). The references to popularized Marxism could be interpreted as a historical legacy of the socialist era. At the same time, they may represent a counter-discourse to the perceived neoliberalism that originated in the West and, again, the perceived erosion of national morality by consumerism. The subject position resonates with the PRC notion of so-called socialist core values, attempting to mix nationalist sentiments with Marxism for contemporary context.

Applying the same framework, Pan $[37]^{13}$ discusses the broad relationship between present-day national security and culture in China. According to his view, cultural security refers primarily to 'political cultural security' (zhengzhi wenhua anquan), including 'political values' (zhengzhi jiazhi) and a 'social management system' (shehui guanli zhi). Adopting a more specific perspective, Shen, Liu, and Ni [43] ${ }^{14}$ link cultural security with soft power. According to them, culture produces security through national cohesion, while maintaining an intact ideology: The prosperity and decline of a nation are dependent upon the rise and fall of the respective culture. ${ }^{15}$ National culture, it is argued, is the historic accumulation of national ethos as a specific 'survival guide' for the nation. Should national culture be weak, a country will lose soft power in competition with other countries. In this sense, they argue, cultural safety is factually tantamount to national sovereignty. Echoing the argument, Li and Shi [30] ${ }^{16}$ bring an application of soft power to the discussion. They examine domestic social management, calling it soft power of the ruling class - 'ruling soft power'. This means that after gaining a ruling position, a class exposes members of society, by mandatory means, to dominant ideology, public opinion, or cultural education to maintain the status quo and the stable development of society. ${ }^{17}$

In this way, the soft power discourse has positioned China's cultural civilization as domestically durable and with external potential, but only under appropriate supervision. In addition to stereotyping traditional culture and Marxism, the discursive argument has been to connect soft power to domestic ethnic harmony in searching for stability and security. $\mathrm{Wu}[55],{ }^{18}$ for example, attempts to demonstrate that a shared cultural communication is inevitably connected to cultural confidence. Here, classification between 'us' and 'them' is produced by proposing dialogue and cultural communication between different ethnic groups in China to 'achieve psychological

\footnotetext{
${ }^{13}$ Pan Yihe, Department of International Cultural Studies, Zhejiang University

${ }^{14}$ Shen Haigang and Ni Yong, Department of Sociology, Shangdong University of Technology / Liu Qingshun, School of Business Administration, Jiangsu University

${ }^{15}$ As an analogy, they mention the Jewish ideology of returning home to Israel after times of hardship and exile. The Zionist power would stem from the Jewish national spirit and culture, the Bible functioning as a cultural carrier (Shen, Liu and Ni 2011: 35 [43])

${ }^{16}$ Li Liaoning and Shi Jun, Marxism College, Hainan University

${ }^{17} \mathrm{Li}$ and Shi give three principles of the "ruling soft power": (1) Only the ruling body can possess ruling soft power, no other individual, social organization, etc.

(2) Ruling soft power is a humane social management repertoire, which is realized through such flexible methods as dominant ideology, cultural education or public opinion, while maintaining people orientation, in other words, people dependency.

(3) The goal of ruling soft power is to advance the position of the ruling body by attracting members of society and obtaining widespread support (Li and Shi 2011, 201 [30]).

${ }^{18} \mathrm{Wu}$ Xianjun, School of Marxism, Fujian Normal University
} 
and cultural appeal under political equality' (shixian zhengzhi pingdeng xia de xinli he wenhua suqiu). According to this logic, as I read it, a diverse range of 55 domestic ethnic minorities should unite towards a common identity of Han culture under the PRC. In advocating such a demarcation, Sun and Wang [47] place at the centre of the soft power construction a cultural security concept that is 'pragmatic, self-confident, open, and pluralistic' (wushi, zixin, kaifang, duoyuan). According to this subject position, pragmatic, pluralism, and open refer to ethnic tolerance.

\section{Supporting Discourse for International Audiences}

Major speeches by China's leading politicians have been translated and made available for English-speaking audiences. To bridge the above domestic discourse to the international one, this section starts by focusing on president Xi Jinping's talk during the 19th Party Congress in 2017. On this occasion, Xi made a case for China's national rejuvenation. He outlined that 'The path of socialist political advancement with Chinese characteristics is the logical outcome of the evolution of history, theory, and practice as the Chinese people have long engaged in struggles since the advent of modern times.' ([9], p. 43). He also encouraged the members of the Communist Party to relentlessly keep on fighting for the cause and to 'fully appreciate the long-term, complex, and onerous of this great struggle; we must be ready to fight, build our ability, and keep striving to secure new victories in this great struggle" ([9], p. 21). With these remarks, $\mathrm{Xi}$ called on those attending the Congress to reflect on the struggles of China and the Party over the past 70 years.

During the Congress, $\mathrm{Xi}$ also outlined the ways in which China, the Party, and Chinese people should go about developing their narrative. He declared that 'We will improve our capacity for engaging in international communication so as to tell China's stories well, present a true, multi-dimensional, and panoramic view of China, and enhance our country's cultural soft power' ([9], p. 52). With cultural soft power he dictated that Chinese people must once again become confident in their culture: 'Without full confidence in our culture, without a rich and prosperous culture, the Chinese nation will not be able to rejuvenate itself' ([9], p. 50). The means to achieve cultural confidence were later underlined by the state news agency Xinhua: 'Chinese President Xi Jinping on Monday called on writers, artists and theorists to strengthen cultural confidence, serve the people with fine works, and guide the public with high moral standards' [28]. It should be noted that Xi formulated the Self as 'prosperous, strong, democratic, culturally advanced, harmonious, and beautiful'. Xi went on to analyse the ways in which the Self has been improved: 'We have committed to examining ourselves in the mirror, tidying our attire, taking a bath, and treating our ailments (...)'. The improved Self has influenced the Other and will continue to do so: 'With this we have seen a further rise in China's international influence, ability to inspire, and power to shape; and China has made great new contributions to global peace and development.'

Echoing the more subtle points raised above by $\mathrm{Xi}$, the notion of a decadent globalization and a corrupt Western culture is frequently highlighted by Chinese state media, often in opinion pieces by Chinese academics, who are quick to point out any shortcomings of Western powers, in particular the USA, in global conduct and preferably in the context of globalization. The discursive practice was recently carried out in 
the Global Times by Professor Cheng Yawen: ${ }^{19}$ "[Globalization] is an instrument that induces weaker states to obey the will of the stronger ones. Globalism is keen on promoting universal values, taking the moral high ground, blaming countries whose actions do not accord with universal values and even intervening militarily in some nations." [8]. At the same time, the same Chinese state-run newspaper noted that: "For a long time, Hollywood movies have played an important role in promoting US culture. The films, as clichéd and predictable as they are, always follow a formula that wraps US core values around universal human stories' [41].

The othering of the USA, while simultaneously depicting the Chinese Self as peaceful, is a discursive practice that is often observed in the Chinese state media, particularly in anonymous editorials. In these, the Other is typically depicted as a hard power and the Self as a soft power: 'Beijing does not want to be dragged into an arms race. But that should not be seen as a sign of weakness, and the military hawks in Washington would commit a grave mistake by underestimating China's determination and capability to protect its sovereignty and territorial integrity, and safeguard regional peace and stability" [12]. While the Chinese Self is depicted as peaceful but strong, the othering of Western actors can even take drastic rhetorical forms such as a China Daily editorial recently formulated: 'And it seems the US - along with its "all-weather friend" across the Atlantic which cannot even manage to clear the Brexit mess of its own making - is hell-bent on doing something stupid, as usual [...]' [13].

It is interesting to note that the Chinese state media discourse appears to seek to destabilize the Western 'Self': '[...] in fact, the elites have always been Western countries' ruling force. [...] The elites help the capital to actualize interests, and thus form a values-interests alliance. Because of such a system, the elites drift away from the common people. [...]Promoting hard-line diplomacy is Western elites' typical act. Western elites benefit most from the old international order' []. This is similar to the popular right-wing arguments in the West that seek to present elites as counterproductive to the lives of the common people, which is rather commonplace in China's state media: 'The Western electoral system cannot solve the problem of political elites drifting away from ordinary people. [...] People from Western countries share the same wish with those from other parts of the world - they all wish for economic development, a good job and decent salary, and a prosperous life' []. In explicating the wishes of Western people, the discursive practice enhances the Chinese Self by distinguishing it from Western democracies. Apparently, the Chinese state excels in providing economic prosperity, as further discussed below.

We can finally observe actual soft power influence of the above identity narrative. It is interesting to notice how the international audience takes part in the discourse, albeit still within China's state media. Professor Zamir Ahmed Awan from Pakistan, for example, writes the following opinion piece on China's struggles in a People's Daily opinion piece: 'But the last 200 years have witnessed suffering due to colonializations, imperialism, and expansionism of the Western world" [1]. He also goes on to empathize with the Chinese Self, which is in line with the above economic arguments: 'From the shortage of food and basic necessities, China now has an abundance of food and a luxury lifestyle. [...] Prosperity is prevailing and a sense of comfort is visible on the faces of Chinese citizens. [...] With the rise of China as a global power, China is

\footnotetext{
19 The School of International Relations and Public Affairs of Shanghai International Studies University
} 
contributing to world peace and proactively participating in international affairs in a positive manner' [1]. Similarly, Robert Lawrence Kuhn writes the following in a People's Daily opinion piece, enhancing China's Self as a successful authoritarian model of governance: "Those who recognize China's unprecedented povertyalleviation success must also recognize its causal relationship to China's system of one-party-leadership rule, and a strong, command-down government. Without such robust authority, it would not seem possible for China to reach its poverty-alleviation goals [...]" [26]. Indeed, as Bially Mattern [4] argues, not everything publicly uttered turns into social facts or reality. The international practitioners of PRC identity discourse, however, appear to support the argument that the academically uttered sociolinguistic interpretations may indeed build soft power in some instances.

\section{Summarized Findings}

Throughout the analysed discourse, the practitioners make overt or latent references to broader global zero-sum competition, where states with weaker identities obey stronger ones. Moreover, Western lead globalization is seen as promoting false universal values and outright immoral behaviour. To counter the influence of decadent Western values and institutions, the PRC discursive practice aims at strengthening Chinese national and cultural identity. The discourse can therefore be regarded as essentially calculated and not emotional, since it contains mainly strategic expressions. It also helps to explain the discourse as a Chinese strategy to simultaneously condemn the present US-led liberal hegemony as disrespectful of China, while building legitimacy for a China-led non-liberal hegemony. Moreover, since the discourse frequently includes inflated self-descriptions, it can be regarded as constructing a hubristic identity for China (culturally advanced/ prosperous/strong/harmonious/beautiful) while at the same time portraying Chinese cultural identity as a vulnerable victim under attack by Western values and institutions. This positions the Self as a soft power, while the Other, in turn, is portrayed as a hard power.

If one examines discursive signs more closely, it is clear that they are produced by frequently contrasting China and the West, assumptions of advanced and less developed cultures, Chinese culture and American culture, developing countries and Western countries, and soft and hard power. Consequently, the discourse returns to those developments of Chinese society that are favourable for stereotyping the Self as vulnerable and under attack. To strengthen this positioning in the discourse, the mental state of the Chinese people is described as a general national apathy. This is positioned as a collective hindrance that is curable by a common culture, ethnic unity, and political stability. Therefore, the future Chinese Self is positioned as ethnically harmonious and socioeconomically stable. As one metaphor used in the discourse literally states, Chinese pursuit of soft power can be seen as a cultural wall constructed to defend the uniqueness of Chinese civilization, which is protected from the threat of Western-led globalization by a confident Chinese identity.

According to the discourse, coherent identity brings about security for the Chinese nation-state. Therefore, it is mandatory for members of society to be exposed to the dominant ideology, with a view to blocking unwanted and false external values such as democracy. This is justified by making use of the affective investment of disrespect. In domestic policy community discourse, in particular, the decadent West is expressed and linked to high levels of emotion, whereas the state media English language discourse 
contains more nuanced and plausible argumentation. This includes highlighting the recent successes of China's authoritarian model in rescuing vast populations from poverty and contrasting this with stagnating economies and problems of democracy in the Western world.

\section{Discussion}

In this study, I conducted an analysis of Chinese soft power-related discourses and connected them to efforts to have the national identity recognized. Since the discourse has various sources involving a large number of participants, it can be regarded as a fairly complex one. Nevertheless, the findings of this study are generally consistent with a number of China studies in suggesting that the PRC constructs legitimacy for the Communist Party through a coherent national identity and soft power (e.g. Johnston [23]; Wuthnow [56]; Shih [44]; Callahan [6]; Ferdinand [15]; Pan [39]).

However, the findings of this study echo Pan et al. (2019) [38] in that disrespect, as invested in the soft power identity, functions as external diplomacy in a broad global context, particularly in the developing world. By contrast, this study does not support the view of Callahan [7], in that the postcolonial victim narrative applies primarily to China's domestic policy. It would appear that strategic disrespect invested in the PRC soft power identity is similar to the South-South cooperation framework that China applies to relations with non-Western nations or those Western countries that have only recently established their identity as 'developed'.

For example, within Chinese foreign policy practices, the post-Soviet Central and Eastern European (CEE) countries, such as the Czech Republic and Hungary, are still regarded as developing'. In fact, according to Bartosz Kowalski [24], in framing SinoCEE relations as South-South cooperation, Chinese foreign policy rhetoric attempts to exploit critical attitudes towards Western values. In the Czech Republic, Chinese rhetoric explains mutual rationale as cooperation of the 'weak and oppressed' ([24], p. 7). Another Eastern European scholar, Anastas Vangeli [50], similarly argues that China's policies towards the $\mathrm{CEE}$ region exploit existing European power relations, in the form of the East's subordination to the West. In doing so, China not only positions the CEE as part of the global South but also attempts to highlight virtues that come with that status.

Regardless how successful China's policy efforts may be, these insights support the view that identity-related soft power, such as China's disrespect discourse, rests on the notion that collective identity narratives may not be limited to national or ethnic markers (see Feklyunina [14], p. 777). By contrast, they can be based on a variety of shared understandings, common interests, and cultural imagery. Moreover, soft power influence that is based on attractive discourses does not require actors to share the same identities; instead, they may find only some aspects of the articulated narratives attractive.

Moreover, the soft power discussed here as a disrespect narrative is similar to broader system narratives proposed by Roselle, Miskimmon, and O'Louglin [42]. According to their view, system-level narratives may make it easier for target audiences to accept individual issue narratives. Therefore, it could be speculated that the promotion of the broader identity narratives, (benevolent Self/Othering of the West), if recognized, could be beneficial for China - also in more specific contexts. In addition to the CEE region, it would also be useful if regional audiences within the South China Sea - for example, in the Philippines, Thailand, 
and Vietnam - were to recognize and share the identity narratives of victimhood and the perception of Western disrespect. The discursive practice of 'Othering' the West could potentially play a key role in countering the soft power of China's regional Western competitors, the USA and Australia. In any case, the PRC appears to strategically maximize China's identity and reduce those of others. This is similar to what Hagstöm and Pan [19] suggest in their recent study. The gist of the discourse is to present the Self as a soft power and the Other as a hard power.

\section{Conclusion}

The mainland Chinese soft power-related discourse appears to rely on inflated descriptions of Self and Other. Albeit framed in a more conciliatory manner, the same descriptions are present in the English-language Chinese state media discourses, which can therefore be included in China's soft power push. The discourse is particularly appealing to shared nonWestern perceptions of disrespect and potentially builds soft power for China in the developing world and in regions where the PRC sees potential for shared victimhood.

Funding Information Open access funding provided by University of Turku (UTU) including Turku University Central Hospital.

Open Access This article is distributed under the terms of the Creative Commons Attribution 4.0 International License (http://creativecommons.org/licenses/by/4.0/), which permits unrestricted use, distribution, and reproduction in any medium, provided you give appropriate credit to the original author(s) and the source, provide a link to the Creative Commons license, and indicate if changes were made.

\section{References}

1. Awan, Zamir Ahmed, People's Daily September 2019: "Seven Decades of China's achievements" <<http://en.people.cn/n3/2019/0912/c90000-9614506.html >>

2. Adler-Nissen, R. and Tsinovoi, A. (2019) "International misrecognition: The politics of humour and national identity in Israel's public diplomacy”. European Journal of International Relations 25(1): 3-29.

3. Barr, M. (2012). Nation Branding as Nation Building: China's Image Campaign. East Asia 29: 81-94.

4. Bially Mattern J. (2005) Why soft power isn't so soft: Representational force and the sociolinguistic construction of attraction in world politics. Millennium: Journal of International Studies 33(3): 583-612.

5. Bobo, L. and Massagli, M. (2001). Stereotyping and urban inequality. In Connor, Tilly, and Bobo (eds.) Urban inequality: Evidence for four cities (pp. 89-162). New York: Russel Sage Foundation.

6. Callahan, W. (2010). China. The Pessoptimist Nation. Oxford: Oxford University Press.

7. Callahan, W. (2015). Identity and Security in China: The Negative Soft Power of the China Dream. Politics. doi: https://doi.org/10.1111/1467-9256.12088.

8. Cheng Yawen, Global Times February 2019: Globalization needs to be upgraded to serve the interest of all people <http:/www.globaltimes.cn/content/1139244.shtml>.

9. Documents of the 19th National Congress of the Communist Party of China (2018). Beijing: Foreign Language Press.

10. Duque, M. (2018) Recognizing International Status: A Relational Approach. International Studies Quarterly (2018) 62: 577-592.

11. Editorial, Global Times September 2019: 'Western elites alienate themselves' < <http://www.globaltimes. $\mathrm{cn} /$ content/1164739.shtml >>

12. Editorial, China Daily September 2019: <<http://global.chinadaily.com.cn/a/201909/16/WS5d7f9500 a310cf3e3556bc1b.html > 
13. Editorial China Daily September 2019: "Hong Kong not a toy the West can play with" < <http://global. chinadaily.com.cn/a/201909/16/WS5d7f91d5a310cf3e3556bc11.html >

14. Feklyunina, V. (2016) Soft power and identity: Russia, Ukraine and the 'Russian world(s)'. European Journal of International Relations 22(4): $773-796$.

15. Ferdinand, P. (2016) Westward ho - the China dream and 'one belt, one road': Chinese foreign policy under Xi Jinping. International Affairs 92(4): 941-957.

16. Greenhill, B. (2008). Recognition and Collective Identity Formation in International Politics. European Journal of International Relations 14(2): 343-368.

17. Gross-Stein, J. (2013).Threat Perception in International Relations. In Huddy, Sears, and Levy (eds.) The Oxford Handbook of Political Psychology (pp. 364-394). New York: Oxford University Press.

18. Gustafsson, K. (2016). Routinised recognition and anxiety: Understanding the deterioration in SinoJapanese relations. Review of International Studies 42(4), 613-633.

19. Hagström, L. and Pan, C. (2019) Traversing the soft/hard power binary: the case of the Sino-Japanese territorial dispute. Review of International Studies 1-19.

20. Hansen, L. (2006). Security as practice: Discourse analysis and the Bosnian War. London: Routledge.

21. He, B. (2013). The Dilemmas of China's Political Science in the Context of the Rise of China. In Guo (ed.) Political Science and Chinese Political Studies: The State of the Field (pp. 193-214). Berlin: Springer-Verlag.

22. Honneth, A. (1992). Integrity and Disrespect. Principles of a Conception of Morality Based on the Theory of Recognition. Political Theory 20(2): 187-201.

23. Johnston, A. (1995). Cultural Realism. Strategic Culture and Grand Strategy in Chinese History. Princeton: Princeton University Press.

24. Kowalski, B. (2017) China's foreignpolicy towards Central and Eastern Europe: The "16 + 1" format in the South-South cooperation perspective. Cases of the Czech Republic and Hungary. Cambridge Journal of Eurasian Studies 1-16.

25. Kinder, D. (2013). Prejudice and Politics. In Huddy, Sears, and Levy (eds.) The Oxford Handbook of Political Psychology (pp.812-851). New York: Oxford University Press.

26. Kuhn, Robert Lawrence, People's Daily September 2019: “Targeted Poverty Alleviation: The China Story that Must Be Told" < <http://en.people.cn/n3/2019/0912/c90000-9614316.html >>

27. Lee, C. (2011). Zhongguo chuantong lunli wenhua ji qi jiazhi de xiandai toushi, (Chi- nese traditional ethics from the perspective of modern culture and values). Xueshu wenti yanjiu (zonghe ban). (Academic Research (Integrated edition) 2: 26-30.

28. Liangyu, Xinhua March 2019: <http://www.xinhuanet.com/english/2019-03/04/c_137868756.htm > .

29. Li, J. (2013). Lun quanqiu hua yu jing xia de wenhua zijue, wenhua zixin he wenhua ziqiang (Globalization and Cultural Consciousness, Cultural Confidence and Cultural Self-improvement). Bei daxue xuebao (zhexue shehui kexue ban) (Journal of Northwest University (Philosophy and Social Sciences Edition)) 43(5), 166-170.

30. Li, L. and Shi, J. (2011). Ruling Soft Power: A Strategy for the Construction of Harmo- nious Society. In Zhu and Zhang, (eds). 2011. Soft Power Innovation and Devel- opment in Today's China. (pp. 201-207). Riverwood: Aussino Academic Publishing House.

31. Lindgren, W.Y. and Lindgren, P. (2017) Identity Politics and the East China Sea: China as Japan's 'Other'. Asian Politics \& Policy 9(3): 378-401.

32. Lindemann, T. (2015). Concluding Remarks on the Empirical Study of International Recognition. In Lindeman and Ringmar (eds.) International Politics of Recognition. New York: Routledge.

33. Liu, D. (2001). Soft Power: the Challenges and Suggestions from American Hegemony. Jilin University Journal Social Sciences Edition.

34. Liu, J. (2006). Several Basic Problems in the construction of China's Soft Power. Affairs Press.

35. Liu, C. (2014). tigao guojia wenhua ruan shili yu weihu woguo yishi xingtai anquan (Enhancing Chinese Cultural Soft Power and Maintaining Ideological Security). Ningxia dangxiao xuebao (Journal of Ningxia Communist Party Institute) 16(1), 58-61.

36. Nye, J. (1990). Soft Power. Foreign Policy 80: 155-171.

37. Pan, Y. (2005). Dangqian guojia tixi zhong de wenhua anquan wenti, (Present national cultural security system). Zhejiang daxue xuebao (renwen shehui kexue ban (Journal of Zhejiang University (Humanities and Social Sciences))) vol 35, no 2, 13-20.

38. Pan, C., Isakhan, B., and Nwokora, Z. (2019) Othering as soft-power discursive practice: China Daily's construction of Trump's America in the 2016 presidential election. Politics 1-16.

39. Pan, C. (2018) Toward a new relational ontology in global politics: China's rise as holographic transition. International Relations of the Asia-Pacific 18: 339-367. 
40. Ringmar, E. (2015). The International Politics of Recognition. In Lindeman and Ringmar (eds.) International Politics of Recognition (pp. 4-23). New York: Routledge.

41. Rong Xiaoqing, Global Times. February 2019: "China catching on to the PR value of movies" < http://www.globaltimes.cn/content/1139622.shtml>

42. Roselle, L., Miskommon, A., and O’Loughlin, B. (2014) Strategic narrative: A new means to understand soft power. Media, War \& Conflict 7(1): $70-84$.

43. Shen, H. Liu, Q. and Ni, Y. (2011). The Analyses of Chinese Cultural Soft Power Based on Cultural Safety. In K. Zhu and H. Zhang (eds.) Soft Power Innovation and Development in Today's China (pp. 3237). Riverwood: Aussino Academic Publishing House.

44. Shih, C-Y. (2013). Sinicizing International Relations. Self, Civilization, and Intellectual Politics in Subaltern East Asia. New York: Palgrave Macmillan.

45. Solomon, T. (2014) The affective underpinnings of soft power. European Journal of International Relations 20(3): 720-741.

46. Su, J. (2013). Zhongguo yìshi xíngtai anquan mianlín de weixie yu zhanlue duice (Men- aces to Chinese Ideology Security and Strategic Countermeasures) Jiangnan shehui xueyuan xuebao Journal of Jiangnan Social University 15(4), 10-15.

47. Sun, Y. \& Wang, Y. (2014). Ruan shili lilun fansi yu zhongguo de wenhua anquan guan (Rethinking the "Soft Power" Theory and A New Concept of China's Cultural Security). Anquan zhanlue (Journal of International Security Studies) 32(2), 101-116.

48. Suzuki, S. (2015). The rise of the Chinese "other" in Japan's construction of identity: Is China a focal point of Japanese nationalism? The Pacific Review 28(1), 95-116.

49. Törrönen, J. (2013). Situational, Cultural and Societal Identities: Analysing Subject Po- sitions as Classifications, Participant Roles, Viewpoints and Interactive Positions. Journal for the Theory of Social Behaviour 44(1): 80-98.

50. Vangeli, A. (2018) Global China and Symbolic Power: The Case of $16+1$ Cooperation. Journal of Contemporary China 27(113): 674-687.

51. Wang, S. Y. (2013). Qian tan quanqiu hua beijing xia zhongguo yingshi ye de minzu wenhua baohu yu chuanbo (Globalization of Chinese film and television industry, protection and dissemination of national culture),. Qi hubei hanshou daxue xuebao (Journal of HUBEI Correspondence University) 26(2): 169-170.

52. Wang, X. (2014). Wenhua zixin yanjiu zongshu (A Review of Researches on Cultural Confidence). Jiangnan shehui xueyuan xuebao (Journal of Jiangnan Social University) 16(1), 71-74.

53. Wu, X. (2011). Quanqiu xing wenhua chuanbo zhong de wenhua shenfen, (Global transmission of cultural identity), Shehui kexuejia, (Social Scientist) 8: 111-114.

54. Wu, G. (2013). Politics Against Science: Reflections on the Study of Chinese Politics in Contemporary China. In Guo (ed.) Political Science and Chinese Political Studies: The State of the Field (pp. 215-236). Berlin: Springer-Verlag.

55. Wu, X. (2014). Zai wenhua jiaowang zhong zengqiang wenhua zixin-jiyu ha bei ma si jiaowang xingwei lilun shijiao (To Boost the Cultural Confidence by the Cultural Communication - Based on the Perspective of Habermas' Communicative Action Theory). Hunan gongcheng xueyuan xuebao (Journal of Hunan Institute of Engineering) 24(2), 77-80.

56. Wuthnow, J. (2008). The Concept of Soft Power in China's Strategic Discourse. Issues \& Studies 44(2): 1-28.

57. Xiao, W. (2013). Quanqiu hua shidai beijing xia woguo yishi xingtai anquan wenti ji zhanlue xuanze (China's Ideological Security Issues and the Strategic Choice in the Context of the Era of Globalization). Huazhong shifan daxue yanjiusheng xuebao (Central China Normal University Journal of Postgraduates) 20(2): 73-76.

58. Zhao, X., Li, X. and Cai, W. (2011). Review of China's Soft Power Research from the Perspective of Local Conversion. In Zhu and Zhang, (eds.) Soft Power Innovation and Development in Today's China. Riverwood: Aussino Academic Publishing House.

59. Zhu, T. and Pearson, M. (2013). Globalization and the role of the state: Reflections on Chinese international and comparative political economy scholarship. Review of International Political Economy 2(6): 1215-1243.

Publisher's Note Springer Nature remains neutral with regard to jurisdictional claims in published maps and institutional affiliations. 